\title{
Effect of acute and chronic exercise on plasma matrix metalloproteinase and total antioxidant levels
}

\author{
Melek Tunc-Ata*, Mukaddes Mergen-Dalyanoglu, Sebahat Turgut, Günfer Turgut \\ Department of Physiology, Pamukkale University Medical Faculty, Denizli, Turkey
}

The relationship between acute and chronic exercise and expression of matrix metalloproteinases (MMPs) in muscles is unknown. There happen some alterations in the oxidant-antioxidant balance due to exercise. This study aimed to investigate the levels of MMP-1, tissue inhibitors of metalloproteinases (TIMP-1), hyaluronic acid (HA), total antioxidant status (TAS), and total oxidant status (TOS) following acute and chronic exercising in rats. Twenty-six Wistar Albino male rats were divided in to three groups: control, acute, and chronic groups. In acute group, treadmill exercise was performed 3 days/wk, 10 min/day for 1 week. In chronic group, exercise performed 7 days/wk, 60 min/day for 4 weeks. At the end of the experiment, plasma MMP-1, TIMP-1, HA, TAS, and TOS levels were measured. In current study, the MMP-1, TIMP-1, $\mathrm{HA}$, and TOS levels not observed statistically significant difference among all groups, but in chronic group, there was a significantly difference $(P<0.05)$ between the control and experimental groups in terms of TAS and oxidative stress index (OSI) levels. TAS, TOS, and OSI levels were significantly different between control and chronic exercise group $(P<0.01, P<0.05$, and $P<0.01$, respectively). According to these results, we can say acute and chronic exercise does not effect on plasma MMP-1, TIMP-1, and HA levels.

Keywords: Acute, Chronic, Exercise, Matrix metalloproteinase

\section{INTRODUCTION}

Thanks to exercise, any bodily activity performed to make the muscles powerful, it is possible to decrease the level of surgical risks and to create a stronger immune system (Hu et al., 2001; Stampfer et al., 2000). The research in the field revealed that exercise mainly strengthens the skeletal muscles (Pedersen, 2013). Matrix metalloproteinases (MMPs) are a family of $\mathrm{Zn}^{++}$and $\mathrm{Ca}^{++}$dependent neutral endopeptidases that degrade components of extracellular matrix (ECM). Exercise-induced injury in skeletal muscle leads to increased expression of MMPs (Carmeli et al., 2005). MMPs are of critical importance in the homeostasis of the ECM in skeletal muscle (Carmeli et al., 2004). Thanks to the ECM surrounding muscle fibers, structural support and protection is enabled and functional integrity of the fibers is maintained (Birkedal-Hansen, 1995). There are some factors that inhibit MMPs. The biological activities of MMPs are antagonized by tissue inhibitor matrix metalloproteinases (TIMPs), such as TIMP-1 (Johnston et al., 2008). MMPs are suppressed by TIMPs with the quality of inhibiting MMPs by binding to their active sites (Jugdutt, 2003; Tsuruda et al., 2004). HA is a high-molecular-weight polysaccharide found throughout the ECM (Chung et al., 2016). A number of several physiological functions and mechanisms are included in HA such as a barrier effect, water homeostasis, stabilizing the ECM (Lieb et al., 2000; Turino and Cantor, 2003). Physical exercise results in numerous alterations in the oxidant-antioxidant balance. There can be seen a number of benefits from moderate exercise which is done regularly. Physical activity increases free radical production and the antioxidant utilization (Cooper et al., 2002; Lachance et al., 2001). There is a negative effect of exhaustive exercise on muscles by creating damage because of increased reactive oxygen species production in the skeletal muscle (Golden et al., 2002).

The aim of this study was investigate the levels of MMP-1, TIMP-1, hyaluronic acid (HA), total antioxidant status (TAS), and total oxidant status (TOS) following acute and chronic exercising in rats.
${ }^{*}$ Corresponding author: Melek Tunc-Ata (iD https://orcid.org/0000-0002-0384-2356 Department of Physiology, Pamukkale University Medical Faculty, Denizli, Turkey Tel: +90-258-296-1729, Fax: +90-258-296-1765, E-mail: tuncmelekk@hotmail.com Received: June 13, 2017 / Accepted: September 13, 2017
This is an Open Access article distributed under the terms of the Creative Commons Attribution Non-Commercial License (http://creativecommons.org/licenses/by-nc/4.0/) which permits unrestricted non-commercial use, distribution, and reproduction in any medium, provided the original work is properly cited. 


\section{MATERIALS AND METHODS}

\section{Animals and experimental conditions}

Twenty-six Wistar Albino 2-month-old male rats (200-250 g) were obtained from the Experimental Research Unit of Our University. They were reared under the supervision of a veterinarian, kept in well-ventilated noises environment and allowed free axes to food and water. They were maintained on a 12/12-hr light-dark cycle under controlled temperature. All protocols used in this study were approved by the Local Ethics Committee on animal research (in our study were used tissues of the animals in study supported with PAUHDEK-2012/035 number).

\section{Experimental design}

The animals were selected randomly and divided into three experimental groups: control $(n=10)$, acute $(n=7)$, chronic $(n=9)$. The control group was not trained (sedentary). Acute exercise group; for 1 week on the treadmill, 3 days/wk, $10 \mathrm{~min} /$ day, $20 \mathrm{~m} /$ min was run. Chronic exercise group; on the treadmill, for 4 weeks, 7 days/wk, $60 \mathrm{~min} /$ day, $0.1 \mathrm{~m} / \mathrm{min}$ was run.

\section{Blood samples and measurements}

When it comes to the end of the experimental period, all the animals were anesthetized with ketamin/xylazine $\mathrm{HCl}(75 \mathrm{mg} /$ $\mathrm{kg} / 10 \mathrm{mg} / \mathrm{kg}$ intraperitoneally). Blood samples were collected in heparinized tubes from the abdominal aorta of rats under anesthesia. Plasma samples were separated from cells by centrifugation at 3,000 rpm for $10 \mathrm{~min}$. and were stored at $-80^{\circ} \mathrm{C}$ until analysis. The plasma MMP-1, TIMP-1, HA concentrations were measured by an enzyme-linked immunosorbent assay (ELISA) method using an rat ELISA kit (Diagnostic Product Corp., Los Angeles, CA,

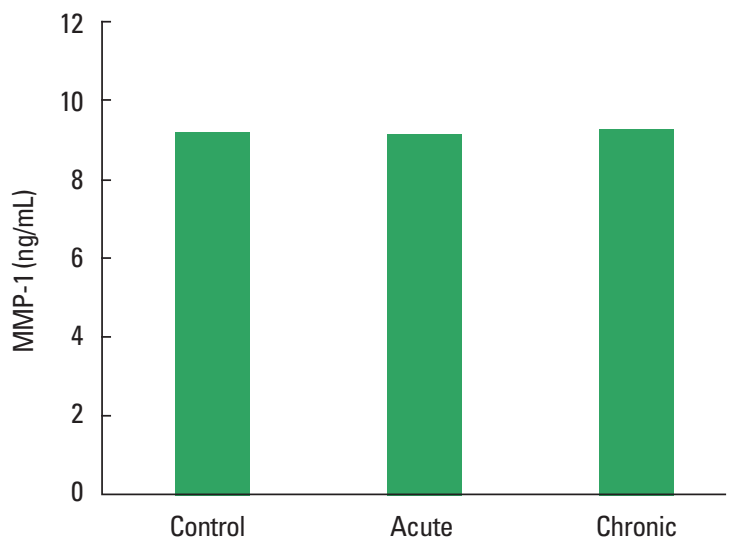

Fig. 1. The comparisons of matrix metalloproteinase-1 (MMP-1) plasma levels in all groups.
USA) in a multiplate ELISA reader (das, Digital and Analog Systems, Vimercate, Italy). Rel-Assay Diagnostic kits use to analyze TAS and TOS level in ELISA microplate reader.

\section{Statistical analysis}

Data was analyzed by IBM SPSS ver. 18.0 (IBM Co., Armonk, NY, USA). Continuous variables were expressed as mean \pm standard deviation and categorical variables as number and percentage. Kruskal-Wallis and Mann-Whitney $U$-test were used for statistical analyses. Relation between continuous variables was analyzed with Pearson correlation coefficient.

\section{RESULTS}

In current study, the MMP-1, TIMP-1, HA, and TOS levels not observed statistically significant difference among all groups (Figs. 1-4). The levels of TAS and OSI (Figs. 5, 6) were significantly different between control and chronic exercise groups. However, no significant difference was seen the between the control and acute exercise groups in terms of the MMP-1, TIMP-1, HA, and TOS concentrations $(P>0.05)$. A significant negative correlation between TIMP-1 and TAS was observed in all rats $(r=$ -0.521, $P=0.006$ ). A negative correlation between TIMP- 1 and TAS was observed in groups separately. But the negative correlation is not statistically significant. The plasma TOS was found to be significantly high in the chronic group compared to the control group $\left(10.73 \pm 2.89\right.$ vs. $7.48 \pm 4.08 \mathrm{mmol}_{2} \mathrm{O}_{2}$ equivalent/L, $P<0.05$ ), whereas plasma TAS was found to be significantly lower in the chronic group than in the control group $(0.95 \pm 0.21$ vs. $1.23 \pm 0.20 \mathrm{mmol} \mathrm{H}_{2} \mathrm{O}_{2}$ equivalent $/ \mathrm{L}, P<0.01$ ) (Figs. 4, 5, respectively). Similar to the plasma TOS values, the OSI value was sig-

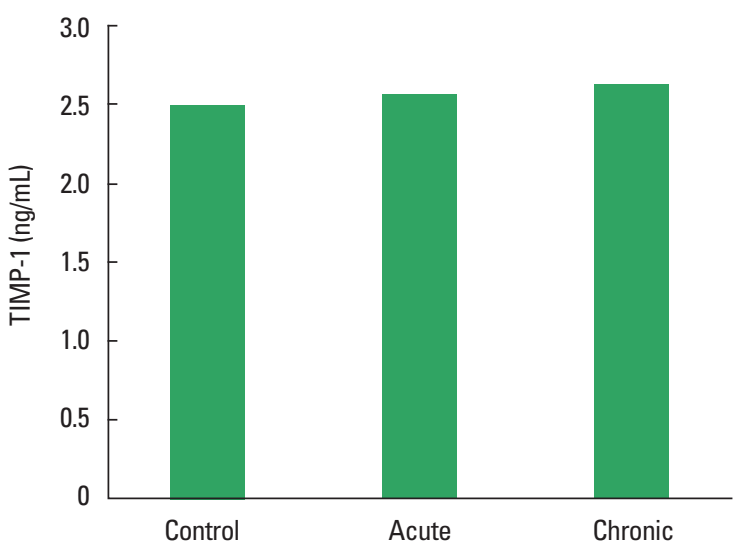

Fig. 2. Tissue inhibitors of metalloproteinases (TIMP-1) plasma levels in groups . 


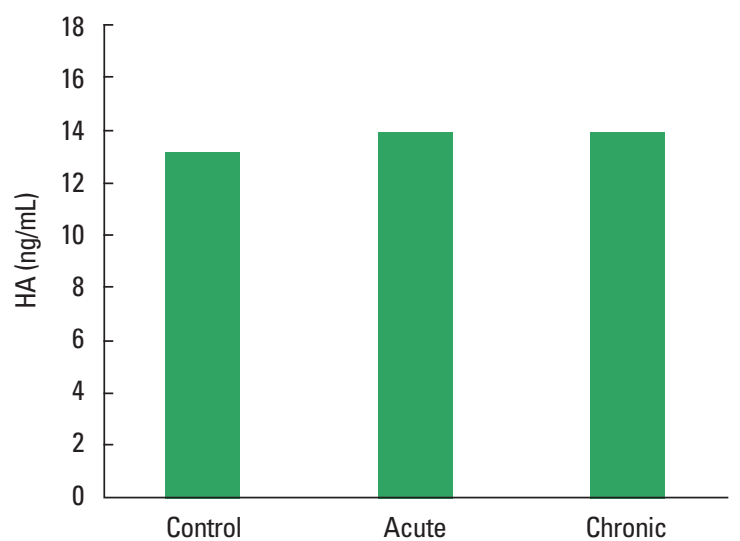

Fig. 3. Hyaluronic acid (HA) plasma levels in groups.

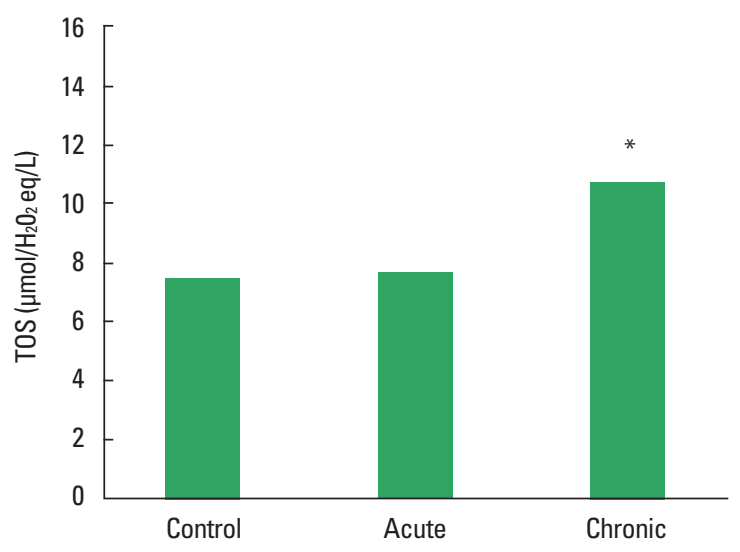

Fig. 4. Total oxidant status (TOS) plasma levels in groups. ${ }^{*} P<0.05$, significant between control and chronic groups.

nificantly higher in the chronic group than in the control group $(1.14 \pm 0.28$ AU vs. $0.64 \pm 0.39$ AU, $P<0.01)$ (Fig. 6).

\section{DISCUSSION}

According to our results, the MMP-1 level was not changed in acute and chronic exercise groups compared to sedentary control group. In a study by Urso et al. (2009), it was reported that the authors characterized the MMP response in human skeletal muscle after acute exercise, and MMP-1 and MMP-3 concentrations increased following 8 weeks of training (Urso et al., 2009). Using a rat model, Carmeli et al. (2005) have reported that the MMP-2 response to training depends on the intensity of exercise, such that high intensity training ( $70 \%$ of maximal oxygen consumption) was needed to increase MMP-2 expression in the gastrocnemius muscle of rats, whereas training at $~ 50 \%$ of maximum was not (Carmeli et al., 2005). Certain stimuli, particularly those that in-

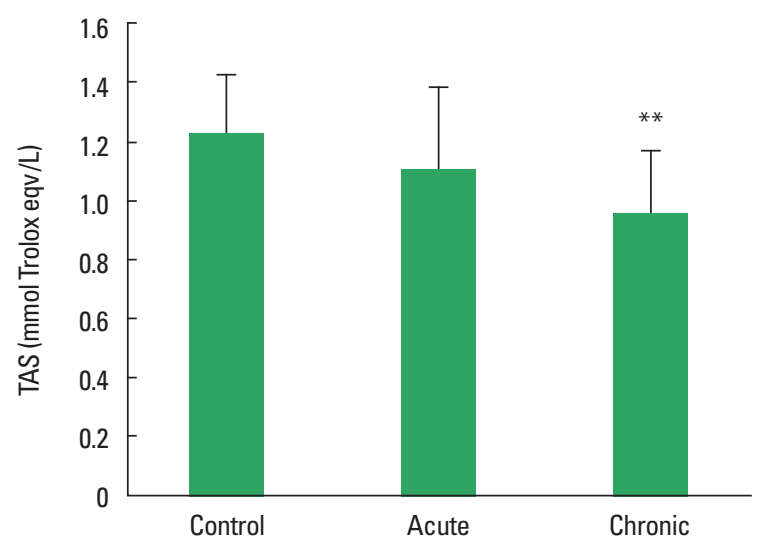

Fig. 5. Total antioxidant status (TAS) levels of serum in the control and chronic groups. ${ }^{*} P<0.01$, significant between control and chronic groups.

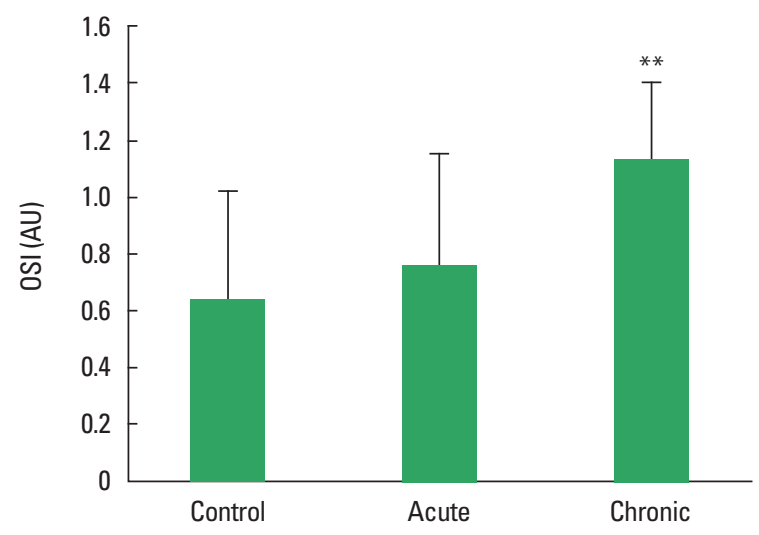

Fig. 6. Oxidative stress index (OSI) values for the control and chronic groups. ${ }^{*} P<0.01$, significant between control and chronic groups.

duce high levels of mechanical stress such as eccentric (Koskinen et al., 2001; Heinemeier et al., 2007) or high-impact exercise (Carmeli et al., 2007) leads to the activation of the local production of MMPs in skeletal muscle. In a study, Rullman et al. (2007) reported that the MMP response in human skeletal muscle was investigated through biopsies taken immediately after a single bout of moderate intensity cycling exercise and it was observed after $120 \mathrm{~min}$. There was an exponential increase in skeletal muscle mRNA and protein for MMP-9 immediately after the exercise until $120 \mathrm{~min}$. Serum concentrations of MMPs are found to be the highest within a relatively short time period following a single bout of exercise (Rullman et al., 2007). Circulating MMP-2 protein is reported to increase in humans within $1 \mathrm{hr}$ after exercise (Suhr et al., 2007). Some important derivations can be made through this data considering the MMP response to exercise in rat or humans. First, it is probable that the MMP response is transient since peak changes occurred either during or within the first 
few hours after an exercise bout. Second, the mechanism of induction might be related to the mode of exercise training or skeletal muscle (e.g., resistance-based training), depending on the nature and intensity of the exercise training (Urso et al., 2009). In our study, the fact that there is no increase in MMP-1 can be explained with the following two reasons; that is, MMP-1 increase was temporary and the level of exercise intensity is not sufficient.

In current study, any significant difference was not observed on TIMP-1 level between exercise and control groups. In the study of Hoier et al. (2012), mRNA levels of TIMP1 was found to be increased in response to acute exercise (after 2 weeks) but they were unaffected by training (after 4 weeks) (Hoier et al., 2012). In another study, thigh-force eccentric muscle contractions increased collagen remodeling and circulating levels of MMP and TIMP in humans and serum TIMP- 1 was significantly elevated on days 1, 2, 3, 4, and 14 postexercise (Mackey et al., 2004). But Madden et al. (2011) showed that plasma levels of TIMP-1, inhibitor of the MMP-9, were also unchanged posteccentric exercise (Madden et al., 2011). In an acute exercise study, an increase in mRNA levels of TIMP-1 was observed as early as $6 \mathrm{hr}$ after exercise. The levels peaked 1 or 2 days after running and attained control values 7 days after running in that study (Koskinen et al., 2001). This findings show that TIMP-1 activation is maintained during the early phase of muscle damage. TIMP-1, the enzyme that inhibits MMP activity seemed to be activated during the early phase of muscle damage. TIMP-1 is expressed in human skeletal muscle and that occurs shortly after exercise (Rullman et al., 2007). In our work is not sufficiently distinct difference between acute and chronic exercise time.

Plasma HA concentrations in our study did not discriminate among all groups. In a study by Hinghofer-Szalkay et al. (2002) six well-trained men performed incremental training until exhaustion (MAX), intensive (submaximal, SUB) and extensive exercise (moderate, MOD) on a bicycle ergometer. When the experimental group and the control group were compared, the plasma hyaluronan concentration (pHA) increased by $76 \%$ during 15 min MAX, by $44 \%$ during 30 -min SUB and by $27 \%$ during $90-$ min MOD. After exercise (15 and $30 \mathrm{~min}$ ), pHA decreased by 43\% levels after MAX $(P<0.05)$ and by $36 \%$ after SUB, respectively. In conclusion, reported that $\mathrm{pHA}$ steadily increased step by step during physical exertion, with a nonlinear increase of concentration/time slope with exercise intensity, the magnitude of the postexercise pHA decrease was proportional to the exercise-induced $\mathrm{pHA}$ increase, that made us think, elevated hyaluronan clearance with rising plasma levels after physical exertion (Hing-
hofer-Szalkay et al., 2002). Hyaluronan is an important safety factor of the edema and might quickly removed from the tissue (Lebel et al., 1988). The effects of exercise on plasma hyaluronan concentration have been shown in the literature. However, there is no clear dose response relations, particularly not those concerning in the decrease of pHA after muscular activity (Piehl-Aulin et al., 1991). In a study show that a significant decrease in hyaluronic acid plasma concentration during this strenuous exercise and authors speculate that decrease in hyaluronic acid concentration was due to an exercise-induced oxidative stress or exercise-induced shear stress enhancing hyaluronic acid incorporation into glycocalyx (Hrabarova et al., 2011).

In our present study, the plasma TOS was found to be significantly higher in the chronic group compared to the control group, whereas plasma TAS was found to be significantly lower in the chronic group than control group. Similar to the plasma TOS values, the OSI value was significantly higher in the chronic group than in the control group. When applied regularly, while moderate exercise has a beneficial effect on human health, intense exercise can produce damage in skeletal muscle and other tissues (McCutcheon et al., 1992). On the other hand, paradoxically exercise can induce oxidative damages. Huang et al. (2013) reported that physical exercise induced oxidative stress which could cause damage to muscle and liver tissues (Huang et al., 2013). Dalla Corte et al. (2013) demonstrated that elevation of oxidative damage markers in the brain, skeletal muscle, and blood after exhaustive exercise (Dalla Corte et al., 2013). The results of all these studies investigating effects of exercise in the literature demonstrated is conflicted. The study results are depending on the type, duration, intensity of the exercise as well as the age at onset of exercise. Maeda et al. (2001) indicated that chronic exercise might decrease oxidative stress probably by inhibiting some oxidative sources. In our work, the total plasma oxidant levels have increased while antioxidant levels decreased, although it is established in scientific literature that TAS levels increase with extended periods of exercise. Therefore, it is speculated that if the time allowed for the exercise had been longer, we may have seen a increase in the total antioxidant levels.

Our results have demonstrated that the MMP-1, TIMP-1, and HA release unchanged as a result of acute and chronic exercise training. Acute and chronic exercise does not have a positive effect on plasma MMP-1 and HA. Plasma TAS did was found to be significantly higher in the control group compared with that of the chronic group. It can say that on the oxidative response to exercise show that it varies with exercise intensity. Acute exercise did not 
have any adverse effect on the oxidant-antioxidant balance. In conclusion, our findings show that further research is needed to determine the functional significance of changes in the MMPs expression and total antioxidant levels in skeletal muscles in response to exercise training.

\section{CONFLICT OF INTEREST}

No potential conflict of interest relevant to this article was reported.

\section{REFERENCES}

Birkedal-Hansen H. Proteolytic remodeling of extracellular matrix. Curr Opin Cell Biol 1995;7:728-735.

Carmeli E, Haimovitz T, Nemcovsky EC. Cathepsin D and MMP-9 activity increase following a high intensity exercise in hind limb muscles of young rats. J Basic Clin Physiol Pharmacol 2007;18:79-86.

Carmeli E, Moas M, Lennon S, Powers SK. High intensity exercise increases expression of matrix metalloproteinases in fast skeletal muscle fibres. Exp Physiol 2005;90:613-619.

Carmeli E, Moas M, Reznick AZ, Coleman R. Matrix metalloproteinases and skeletal muscle: a brief review. Muscle Nerve 2004;29:191-197.

Chung HC, Bak H, Lee JW, Ahn SK. A rare cutaneous adverse reaction after intra-articular injection of hyaluronic acid. Ann Dermatol 2016; 28:529-531.

Cooper CE, Vollaard NB, Choueiri T, Wilson MT. Exercise, free radicals and oxidative stress. Biochem Soc Trans 2002;30:280-285.

Dalla Corte CL, de Carvalho NR, Amaral GP, Puntel GO, Silva LF, Retamoso LT, Royes LF, Bresciani GB, da Cruz IB, Rocha JB, Barrio Lera JP, Soares FA. Antioxidant effect of organic purple grape juice on exhaustive exercise. Appl Physiol Nutr Metab 2013;38:558-565.

Golden TR, Hinerfeld DA, Melov S. Oxidative stress and aging: beyond correlation. Aging Cell 2002;1:117-123.

Heinemeier KM, Olesen JL, Haddad F, Langberg H, Kjaer M, Baldwin $\mathrm{KM}$, Schjerling P. Expression of collagen and related growth factors in rat tendon and skeletal muscle in response to specific contraction types. J Physiol 2007;582(Pt 3):1303-1316.

Hinghofer-Szalkay HG, Mekonen W, Rössler A, Schwaberger G, Lamprecht $\mathrm{M}$, Hofmann P. Post-exercise decrease of plasma hyaluronan: increased clearance or diminished production? Physiol Res 2002;51: 139-144.

Hoier B, Nordsborg N, Andersen S, Jensen L, Nybo L, Bangsbo J, Hellsten Y. Pro- and anti-angiogenic factors in human skeletal muscle in response to acute exercise and training. J Physiol 2012;590:595-606.
Hrabarova E, Juranek I, Soltes L. Pro-oxidative effect of peroxynitrite regarding biological systems: a special focus on high-molar-mass hyaluronan degradation. Gen Physiol Biophys 2011;30:223-238.

Hu FB, Manson JE, Stampfer MJ, Colditz G, Liu S, Solomon CG, Willett WC. Diet, lifestyle, and the risk of type 2 diabetes mellitus in women. N Engl J Med 2001;345:790-797.

Huang KC, Wu WT, Yang FL, Chiu YH, Peng TC, Hsu BG, Liao KW, Lee RP. Effects of freshwater clam extract supplementation on time to exhaustion, muscle damage, pro/anti-inflammatory cytokines, and liver injury in rats after exhaustive exercise. Molecules 2013;18:3825-3838.

Johnston P, Larson D, Clark IM, Chojnowski AJ. Metalloproteinase gene expression correlates with clinical outcome in Dupuytren's disease. J Hand Surg Am 2008;33:1160-1167.

Jugdutt BI. Remodeling of the myocardium and potential targets in the collagen degradation and synthesis pathways. Curr Drug Targets Cardiovasc Haematol Disord 2003;3:1-30.

Koskinen SO, Höyhtyä M, Turpeenniemi-Hujanen T, Martikkala V, Mäkinen TT, Oksa J, Rintamäki H, Löfberg M, Somer H, Takala TE. Serum concentrations of collagen degrading enzymes and their inhibitors after downhill running. Scand J Med Sci Sports 2001;11:9-15.

Lachance PA, Nakat Z, Jeong WS. Antioxidants: an integrative approach. Nutrition 2001;17:835-838.

Lebel L, Smith L, Risberg B, Gerdin B, Laurent TC. Effect of increased hydrostatic pressure on lymphatic elimination of hyaluronan from sheep lung. J Appl Physiol (1985) 1988;64:1327-1332.

Lieb T, Forteza R, Salathe M. Hyaluronic acid in cultured ovine tracheal cells and its effect on ciliary beat frequency in vitro. J Aerosol Med 2000;13:231-237.

Mackey AL, Donnelly AE, Turpeenniemi-Hujanen T, Roper HP. Skeletal muscle collagen content in humans after high-force eccentric contractions. J Appl Physiol (1985) 2004;97:197-203.

Madden MC, Byrnes WC, Lebin JA, Batliner ME, Allen DL. Plasma matrix metalloproteinase-9 response to eccentric exercise of the elbow flexors. Eur J Appl Physiol 2011;111:1795-1805.

Maeda S, Miyauchi T, Kakiyama T, Sugawara J, Iemitsu M, Irukayama-Tomobe Y, Murakami H, Kumagai Y, Kuno S, Matsuda M. Effects of exercise training of 8 weeks and detraining on plasma levels of endothelium-derived factors, endothelin-1 and nitric oxide, in healthy young humans. Life Sci 2001;69:1005-1016.

McCutcheon LJ, Byrd SK, Hodgson DR. Ultrastructural changes in skeletal muscle after fatiguing exercise. J Appl Physiol (1985) 1992;72:11111117.

Pedersen BK. Muscle as a secretory organ. Compr Physiol 2013;3:13371362.

Piehl-Aulin K, Laurent C, Engström-Laurent A, Hellström S, Henriksson 
J. Hyaluronan in human skeletal muscle of lower extremity: concentration, distribution, and effect of exercise. J Appl Physiol (1985) 1991;71:2493-2498.

Rullman E, Rundqvist H, Wågsäter D, Fischer H, Eriksson P, Sundberg CJ, Jansson E, Gustafsson T. A single bout of exercise activates matrix metalloproteinase in human skeletal muscle. J Appl Physiol (1985) 2007;102:2346-2351.

Stampfer MJ, Hu FB, Manson JE, Rimm EB, Willett WC. Primary prevention of coronary heart disease in women through diet and lifestyle. $\mathrm{N}$ Engl J Med 2000;343:16-22.

Suhr F, Brixius K, de Marées M, Bölck B, Kleinöder H, Achtzehn S, Bloch
W, Mester J. Effects of short-term vibration and hypoxia during high-intensity cycling exercise on circulating levels of angiogenic regulators in humans. J Appl Physiol (1985) 2007;103:474-483.

Tsuruda T, Costello-Boerrigter LC, Burnett JC Jr. Matrix metalloproteinases: pathways of induction by bioactive molecules. Heart Fail Rev 2004;9:53-61.

Turino GM, Cantor JO. Hyaluronan in respiratory injury and repair. Am J Respir Crit Care Med 2003;167:1169-1175.

Urso ML, Pierce JR, Alemany JA, Harman EA, Nindl BC. Effects of exercise training on the matrix metalloprotease response to acute exercise. Eur J Appl Physiol 2009;106:655-663. 